\title{
Efficient culture system for human embryonic stem cells using autologous human embryonic stem cell-derived feeder cells
}

\author{
Seung Jun Yoo ${ }^{1,2}$, Byung Sun Yoon ${ }^{1}$, \\ Jin Mee Kim ${ }^{1}$, Ji Min Song ${ }^{1}$, \\ Sung II Roh ${ }^{1}$, Seungkwon You ${ }^{2,4}$ \\ and Hyun Soo Yoon 3,4 \\ ${ }^{1}$ Laboratory of Stem Cell Research \\ Medical Research Center, MizMedi Hospital \\ 701-4 Naebalsan-dong, Kangseo-gu \\ Seoul 157-280, Korea \\ ${ }^{2}$ Laboratory of Cell Function Regulation \\ Division of Biotechnology and Genetic Engineering \\ College of Life and Environmental Sciences, Korea University \\ 1, 5-ga, Anam-dong, Sungbuk-gu \\ Seoul 136-701, Korea \\ ${ }^{3}$ Department of Anatomy and Cell Biology \\ College of Medicine, Hanyang University \\ 17 Haengdang-dong, Seongdong-gu \\ Seoul 133-792, Korea \\ ${ }^{4}$ Corresponding authors: Tel, 82-2-2220-0602 (HS Yoon), \\ 82-2-3290-3057 (S You); \\ Fax, 82-2-2281-7841 (HS Yoon), 82-2-3290-3507 (S You); \\ E-mail, hsyoon@hanyang.ac.kr (HS Yoon), \\ bioseung@korea.ac.kr (S You)
}

\section{Accepted 9 August 2005}

Abbreviations: AP, alkaline phosphatase; bFGF, basic fibroblast growth factor; Diff Miz-hES6 cells, feeder cells differentiated from Miz-hES6hESCs;EB,embryoidbody;FBS,fetalbovineserum;hESC, humanembryonicstemcell;MEF, mouseembryonicfibroblast;SSEA, stagespecificembryonicantigen

\begin{abstract}
Humanembryonicstemcells(hESCs)needfeeder cells for theirmaintenance in an undifferentiated state. In conventional culture systems, mouse embryonicfibroblasts(MEFs)serveasfeedercells to maintain hESCs. However, the use of MEFs elevatestheriskoftransmittingmousepathogens and thus limits the potential of hESCs in cell replacement therapy. Consequently, the use of human feeder cells would be an important step forwardinthis invitro technology.Toaddressthis issue, we used fibroblast-like cells differentiated fromtheMiz-hES6hESCline(Diff Miz-hES6) asfeeder cellstosupportthe invitro growthofthreehESC
\end{abstract}

lines. Immunofluorescence microscopy and reversetranscription-PCR assessingtheexpression ofundifferentiatedhESC markersrevealedalthree hESClinesweremaintainedinanundifferentiated state. Invitro proliferationproceededasefficiently aswhenthehESCswereculturedonMEFS.More over,karyotypeanalysisrevealedthechromosomal normalityofthehESClinesandtheDiff ${ }_{\text {Miz-hESG }}^{\text {feeders }}$ themselvesaftereven50passages.Furthermore,the hESClinesmaintainedthei rpluripotencysincethey remainedcapableofformingembryoidbodies(EBs) in vitro. Thus, hESC-derived fibroblast-like cells successfullysupport invitro hESCpropagation.

Keywords:cellculturetechniques;humans;stemcells; stemcelltransplantation

\section{Introduction}

Embryonic stem cells (ESCs) can differentiate into all the cells derived from three embryonic germ layers (Choi et al., 2004; Kim et al., 2005a; b). Human embryonic stem cells (hESCs) are derived frominnercellmassesofhumanblastocysts (Thomson et al., 1998). The two fundamental characteristics ofhESCsare theirpluripotency and capacity for self- renewal. For the long-term culture of hESCs, feeder cell layers are conventionally used. Feeder cells are believed to help maintain hESCs by providing cell-cellcontactwithhESC coloniesand/orby providingmanysecretingfactors, which havenotyet beenfullyidentified.

To date, the most commonly used feeder cells are primary MEFs, which are prepared from day 13.5 postcoitumfetusesofpregnantmice. However,MEFs haveseveralseriouslimitationsasfeedercells.First, they havealimited lifespanincultureas the culture can only be passaged seven to nine times before the feeder cells senesce. Second, the use of MEFs introduces the risk of contaminating hESCs with animal pathogens. Due to these considerations, itis desirable to use fresh stocks of feeder cells that originate from human sources in the in vitro culture ofhESCs.

Recently, weandothergroups demonstrated thatit is possible to culture hESCs on feeder cells that originatefromhumansources(Richards etal., 2002; 2003;Amit etal., 2003a;Cheng etal., 2003; Hovatta 
et al., 2003; Lee et al., 2005). In most cases, however, these human feeder cell lines are derived from samples obtained from patients or discarded human fetuses. This may seriously limit the accessibility of these feeder cells to researchers in the field. In addition, it is important to standardize the source of feeder cells used for research, as this is a variable that could hamper comparison between results obtained by different groups.

Feeder-free culture of hESCs has been reported (Xu et al., 2001; Amit et al., 2003b; Rosler et al., 2004). However, this method does require media conditioned by MEFs cultured with fetal bovine serum (FBS). Moreover, the stable and long-term culture of hESCs and the maintenance of their undifferentiated state still requires feeder cells along with the addition of exogenous basic fibroblast growth factor (bFGF) (Kim et al., 2005c).

In the present study, we report the method we developed to supply human feeder cells for hESC culture. These feeder cells are themselves derived from hESCs, namely, the Miz-hES6 hESC line, and

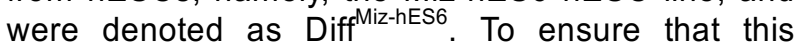
feeder layer fully meets its in vitro requirements, we compared the growth rate, undifferentiated phenotype, pluripotency, and genomic integrity of three hESC lines grown over a prolonged period with the human feeders or with MEF feeder cells. The undifferentiated phenotype was assessed by reverse transcription-polymerase chain reaction (RT-PCR) and immunofluorescence microscopy for undifferentiated markers, while pluripotency was assessed by the capacity of the hESC lines to form embryoid bodies (EBs) in vitro, which were analyzed by RTPCR using primers specific for the three germ layers. We found that hESC-derived feeder cells maintain hESC lines in an undifferentiated, karyotypically-intact state. These autologous hESC-derived fibroblast-like feeders can be easily accessed by researchers and aid the development of a xenofree hESC culture system, thus promoting the safety of cell replacement therapy.

\section{Materials and Methods}

\section{Preparation of Diff ${ }^{\mathrm{Miz}-\mathrm{hES} 6}$ cells}

All cell cultures were incubated at $37^{\circ} \mathrm{C}$ in $5 \% \mathrm{CO}_{2}$ in air and 95\% humidity. The Miz-hES6 hESC line (Kim et al., 2005d) was mechanically dissociated and induced to differentiate spontaneously in DMEM (no pyruvate, high glucose) supplemented with $1 \%$ nonessential amino acids, $0.1 \mathrm{mM} \beta$-mercaptoethanol, $100 \mathrm{U} / \mathrm{ml}$ penicillin $\mathrm{G}, 100 \mathrm{~g} / \mathrm{ml}$ streptomycin, sodium bicarbonate (all from Invitrogen) and 10\% FBS (HyClone). The line was subsequently passaged ac- cording to the standard 3T3 protocol. The resulting differentiated cells, which are denoted as Diff ${ }^{\mathrm{Miz}-\mathrm{hES}}{ }^{\text {, }}$ were maintained in DMEM $10 \%$ FBS until a consistent morphology was observed. The cells were passaged every $3-5$ days with $0.05 \%$ trypsin- EDTA (Invitrogen). From the $6^{\text {th }}$ passage, Diff ${ }^{\text {Miz-hES6 }}$ cells could be continuously cultured until their $30^{\text {th }}$ passage, at which point the cells senesced (data not shown).

\section{Use of Diff ${ }^{\text {Miz-hES6 }}$ cells as feeder cells}

When the Diff ${ }^{\text {Miz-hES6 }}$ cells reached the subconfluent state after passaging, they were mitotically inactivated by treatment with $10 \mu \mathrm{g} / \mathrm{ml}$ mitomycin $\mathrm{C}$ (Sigma) for $1.5 \mathrm{~h}$. The cells were then thoroughly washed in PBS, trypsinized with $0.05 \%$ trypsinEDTA and replated at a concentration of $3.25 \times 10^{4}$ cells $/ \mathrm{cm}^{2}$ in gelatin-coated 4 -well culture dishes.

\section{Culture of hESCs}

We cultured the Miz-hES1 and Miz-hES4 hESC lines (Kim et al., 2005d) and the HSF-6 hESC line from the University of California at San Francisco. The former two lines are male cell lines. The Miz-hES1 line is registered on the NIH hESC Registry along with the HSF-6 cell line. The three hESC lines were initially maintained on MEF feeder cells and then transferred onto Diff ${ }^{\text {Miz-hES6 }}$ cells. They were cultured at $37^{\circ} \mathrm{C}$ in $5 \% \mathrm{CO}_{2}$ in air and $95 \%$ humidity with DMEM/F12 media supplemented with $4 \mathrm{ng} / \mathrm{ml} \mathrm{bFGF}$, $20 \%$ Knockout Serum Replacement, 1\% nonessential amino acids, $0.1 \mathrm{mM} \beta$-mercaptoethanol, 100 $\mathrm{U} / \mathrm{ml}$ penicillin $\mathrm{G}$ and $100 \mathrm{~g} / \mathrm{ml}$ streptomycin (all from Invitrogen). The hESCs were passaged every 3-5 days by mechanically dissociating hESC clumps and transferring them onto newly prepared Diff ${ }^{\text {Miz-hES6 }}$ feeder cell layers.

\section{Staining of hESCs for undifferentiated cell markers and immunofluorescence analysis}

After the $20^{\text {th }}$ passage of the three hESC lines cultured on Diff ${ }^{\text {Miz-hES6 }}$ or MEF feeder cells, the hESCs were stained for undifferentiated hESC markers, namely, alkaline phosphatase (AP), stage-specific embryonic antigen-1 (SSEA-1), SSEA-4, and Tra-1-60 (Chemicon). AP staining was performed by using the NBT/BCIP solution (Roche) with $1: 100$ in Tris- $\mathrm{HCl}, \mathrm{pH}$ 9.5. The anti-SSEA-1 and anti-Tra-1-60 antibodies are mouse $\lg M$ antibodies, while the anti-SSEA-4 antibody is a mouse IgG antibody. All primary antibodies were diluted at 1:1,000 and incubated with the cells for $1 \mathrm{~h}$ at room temperature. After washing, the cells were incubated for $45 \mathrm{~min}$ at 
room temperature withoutlightexposurewith 1:400diluted FITC-labelled secondary antibodies specific for mouse $\operatorname{lgM}$ or $\lg \mathrm{G}$. The resulting images were monitoredbyafluorescentmicroscope(Nikon).

\section{In vitro formation and RT-PCR analysis of EBs}

To test the pluripotency of hESCs cultured on Diff $^{\text {Miz-hES6 }}$ feeder cells, we analyzed their ab ility to form EBs by transferring dissociated clumps of $\mathrm{hESC}$ colonies onto Petri dishes in EB suspension medium (hESC medium lacking bFGF). The EBs were continuously cultured in suspension until days 7 and 14, at which point they were subjected to RT-PCRbyusing primersspecificforthethreegerm layers, namely, ectoderm (primers specific for Neurofilament 68 and keratin), mesoderm (primers specificfor enolase and ka llikrein) and endoderm (primers specific for $\alpha$-fetoprotein $[\alpha-F P]$ and $\alpha 1$-antitrypsin [ $\alpha 1-A T])$. The amplified bands were quantified bya densitometerand the data were presented asrelativedensities.

\section{RT-PCR}

Thesequencesoftheprimerusedarelistedin Table 1.ThePCRsconsistedofaninitialdenaturationstep at $94{ }^{\circ} \mathrm{C}$ for $5 \mathrm{~min}$ followed by 30 cycles of 30 secof denaturation at $94{ }^{\circ} \mathrm{C}, 30$ sec of annealing at $62{ }^{\circ} \mathrm{C}$, and 30 sec of extension at $72 \quad{ }^{\circ} \mathrm{C}$. A final extension was performed at $72{ }^{\circ} \mathrm{C}$ for $10 \mathrm{~min}$. PCR products werevisualized by ethidium bromide staining following 1.0\%agarosegelelectrophoresis.

\section{Karyotype analysis}

Toanalyze the karyotypesoftheDiff ${ }^{\text {Miz-hES6 }}$ cellsand the HSF-6 and Miz-hES4 hESC lines cultured on Diff $^{\text {Miz-hES6 }}$ feeder cells, cell division was blocked in metaphaseby $0.1 \mu \mathrm{g} / \mathrm{mlcolcemid(Gibco/Invitrogen)}$ for 1-2 $\mathrm{h}$. The cells were then trypsinized and resuspended in hypotonic $\mathrm{KCl}$ solution (Sigma),

Table 1. Information on RT-PCR primers.

\begin{tabular}{|c|c|c|c|}
\hline Genes & Primersequences(Forward,Reverse) & $\left.{ }^{\circ} \mathrm{C}\right)$ & Productsize(bp) \\
\hline \multicolumn{4}{|l|}{ UndifferentiatedhESCmarkers } \\
\hline Nanog[NG_004093] & $\begin{array}{l}\text { F:CAAA GGCAAACAACCCACTT } \\
\text { R:CTGGATGTTCTGGGTCTGGT }\end{array}$ & 62 & 426 \\
\hline Oct4[NM_013633] & $\begin{array}{l}\text { F:GACAACAATGAGAACCTTCA } \\
\text { R:TTCTGGCGCCGGTTACAGAA }\end{array}$ & 62 & 218 \\
\hline Rex1[NM_174900] & $\begin{array}{l}\text { F:CTG AAGAAACGGGCAAAGAC } \\
\text { R:GAACATTCAAGGGAGCTTGC }\end{array}$ & 62 & 344 \\
\hline Sox2[NM_003106] & $\begin{array}{l}\text { F:ATGGACAGTTACGCGCACAT } \\
\text { R:GACTTGACCACCGAACCCAT }\end{array}$ & 62 & 268 \\
\hline \multicolumn{4}{|l|}{ Invitro differentiationmarkers } \\
\hline NF-68[NM_006158] & $\begin{array}{l}\text { F:ACGCTGAGGAATGGTTCAAG } \\
\text { R:TAGACGCCTCAATGGTTTCC }\end{array}$ & 62 & 561 \\
\hline Keratin[NM_173086] & $\begin{array}{l}\text { F:A GGCCCAATACGAGGAGATT } \\
\text { R:ATAGCCACTGGAGATGGTGG }\end{array}$ & 62 & 479 \\
\hline Kallikrein[NM_000537] & $\begin{array}{l}\text { F:GCTTTCTCAGCCAGGACATC } \\
\text { R:TATTCTTTGCCTCCCAGGTG }\end{array}$ & 62 & 562 \\
\hline Enolase[NM_001428] & $\begin{array}{l}\text { F:GTTCAATGTCATCAATGGCG } \\
\text { R:GTGAACTTCTGCCAAGCTCC }\end{array}$ & 62 & 477 \\
\hline$\alpha-F P\left[N M \_001134\right]$ & $\begin{array}{l}\text { F:TGAAAACCCTCTTGAATGCC } \\
\text { R:TCTTGCTTCATCGTTTGCAG }\end{array}$ & 62 & 492 \\
\hline a1-AT[NM_001002236] & $\begin{array}{l}\text { F:ACTG TCAACTTCGGGGACAC } \\
\text { R:CCCCATTGCTGAAGACCTTA }\end{array}$ & 62 & 517 \\
\hline \multicolumn{4}{|l|}{ Housekeepinggene } \\
\hline$\beta$-actin[BC_013835] & $\begin{array}{l}\text { F:AGCAAGCAGGAGTATGACGA } \\
\text { R:TGTGAACTTTGGGGGATGGA }\end{array}$ & 62 & 260 \\
\hline \multicolumn{4}{|l|}{ Celltypingmarkers } \\
\hline $\begin{array}{l}\text { Prolyl4-hydroxylase } \beta \\
\text { (Fibroblastmarker) }\end{array}$ & $\begin{array}{l}\text { F:GTCTTTGTGGAGTTCTATGCCC } \\
\text { R:GTCATCGTCTTCCTCCATGTCT }\end{array}$ & 62 & 339 \\
\hline $\begin{array}{l}\text { Cytokeratin4 } \\
\text { (Epithelialcellmarker) }\end{array}$ & $\begin{array}{l}\text { F:ACTGGTGTCTCTGTGCTTCCTT } \\
\text { R:GGGTGTTGGAGAAGTAGTTTGG }\end{array}$ & 62 & 359 \\
\hline
\end{tabular}


incubated for $20 \mathrm{~min}$ at $37^{\circ} \mathrm{C}$, and fixed with $3: 1$ methanolacetic acid. The chromosomes were visualized by $\mathrm{G}$-band staining. More than 100 cells were analyzed per cell line.

\section{Results}

Generation and characterization of fibroblast-like
Diff ${ }^{\text {Mtz-hES6 }}$ cells
Diff ${ }^{\text {Miz-hES6 }}$ cells were spontaneously differentiated from the Miz-hES6 hESC line. To do this, undifferentiated Miz-hES6 cells were mechanically dissociated into clumps and transferred onto a culture dish containing DMEM $/ 10 \%$ FBS. After the $3-5^{\text {th }}$ passage, homogeneous fibroblast-like differentiated Diff ${ }^{\text {Miz-hes }}$ cells were obtained (Figure 1A and $1 \mathrm{~B}$ ). To further verify the identity of the feeder cells, we subjected them to RT-PCR using PCR primers for cytokeratin 4 (an epithelial cell marker) and prolyl 4-hydroxylase B (a fibroblast marker). As expected, prolyl 4-hydroxylase $\beta$ but not cytokeratin 4 is expressed by the Diff $^{\mathrm{MizhES6}}$ cells, which indicates that Diff ${ }^{\mathrm{Miz}-\mathrm{hES} 6}$ cells are fibroblasts (Figure 1C).

\section{Long-term support of hESC growth on Diff ${ }^{\text {ito-hes6 }}$ feeder cells}

The three hESC lines Miz-hES1, Miz-hES4 and
HSF-6 were initially cultured on MEF feeder cells and then transferred onto Diff ${ }^{\text {Miz-hES6 }}$ feeder cells. At this point, the Diff ${ }^{\mathrm{Mz}-\mathrm{hES} 6}$ feeder cells had undergone 6 passages, while the individual hESC lines were at passage numbers 34,107 and 54, respectively. All three hESC lines cultured on Diff ${ }^{\text {Miz-hES6 }}$ feeder cells grew at a similar rate as those on MEF feeder cells, as they required a 3-5 day passaging interval. Thus, Diff $^{\mathrm{Mz}-\mathrm{nES} 6}$ feeder cells support the proliferation of hESCs as efficiently as MEFs. In contrast, the literature suggests hESCs cultured on other human feeder cells require a 5-7 day passaging interval (data not shown) (Richards et al., 2002; 2003; Amit et al., 2003a; Cheng et al., 2003; Hovatta et al., 2003; Lee et al., 2005). The hESC lines cultured on Diff $^{\mathrm{ML}-\mathrm{hES} 6}$ feeder cells were relatively circular in shape (Figure 2), which is similar to their morphology when cultured on MEF feeder cells (data not shown). In contrast, the literature suggests hESCs cultured on other human feeder cells become rather irregular in shape (Richards et al., 2002; 2003; Amit et al., 2003a; Cheng et al., 2003; Hovatta et al., 2003; Lee et al., 2005). We could culture the three hESC lines on Diff ${ }^{\text {Miz-hes6 }}$ cells for over 50 passages without any detecatable impairment of their self-renewal capacity (data not shown).
A

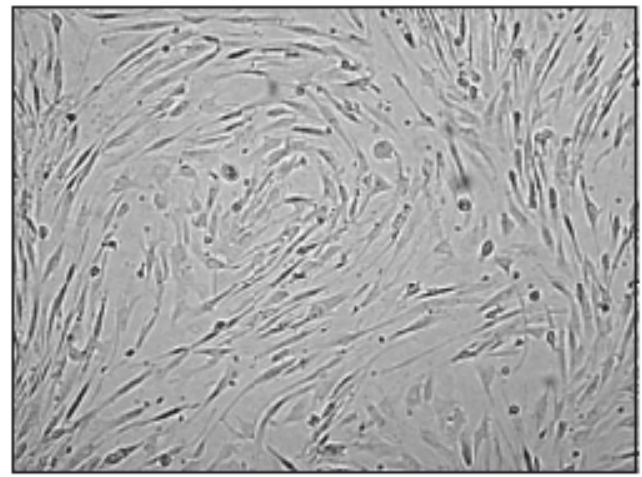

$(\times 40)$
B

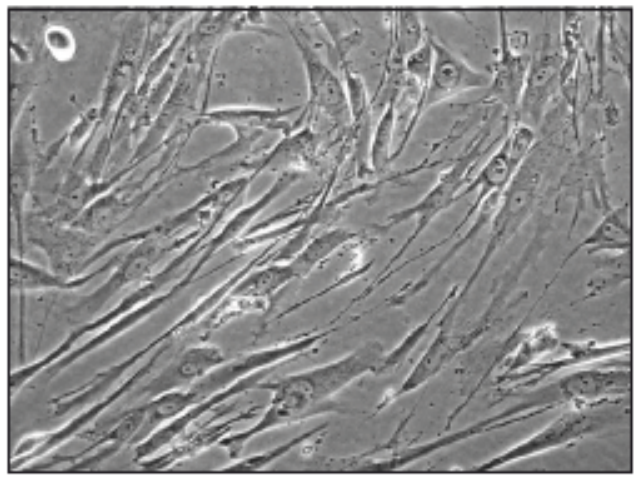

$(\times 200)$
C

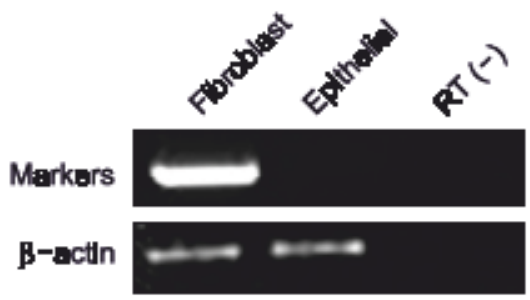

Figure 1. Morphology of Diff ${ }^{\text {Mthess }}$ cells. Miz-hES1 hESCs were differentiated in vitto by growth in DMEM/10\% FBS. The Diff ${ }^{\text {NehES3 }}$ cells shown here were examined after 3.5 passages. (A, B) Fibroblast-ilike morphology of Diff ${ }^{\text {Mztes }}$ cells. Magnification is $40 \times$ (A) and $200 \times(B)$. (C) RT-PCR for fibroblast (prolyl 4-hydroxylase $\bar{B}$ ) and epithelial cell (cytokeratin 4) markers to verily the idenfity of the Diff ${ }^{\text {MEthess }}$ cells. RT(-), PCR was performed without reverse transcription. 


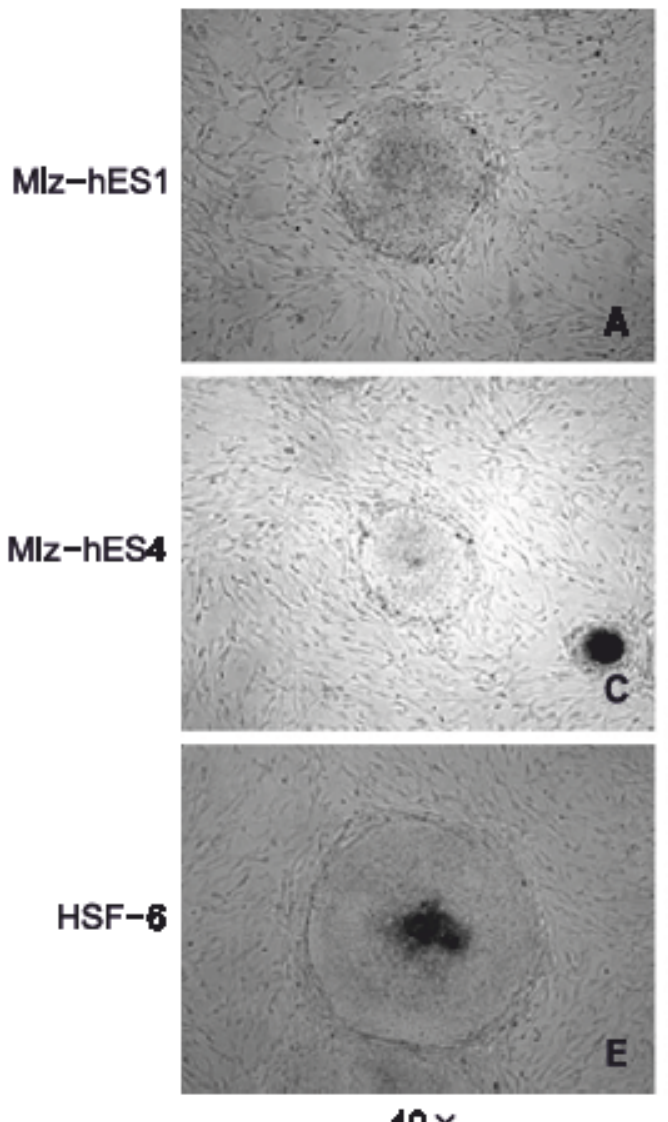

$40 \times$
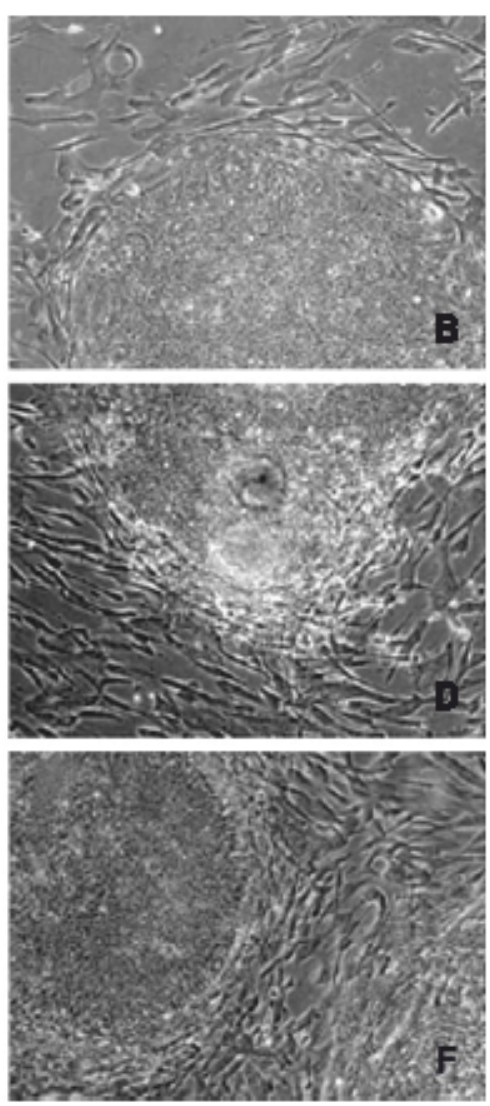

$100 x$
Figure 2. Morphology of the three $h E S C$ lines after their cullure on the Difflitetest feeder layer. The cells were examined at two different magnifications, namely, 40 $\times(A, C, E)$. and $200 \times(B, D, F$. Miz-hES1 (A, B), Miz-hES4 (C, D) and HSF $-6(E, F)$. The morphology of the three hESC lines was similar to when they were cultured on MEF feeder cells (data not shown).

\section{Expression of hESC markers by hESC lines cultured on Diff ${ }^{\text {Mzhes6 }}$ feeder cells}

hESCs express specific markers such as Oct-4, Nanog, Rex-1, Sox-2, TERT, SSEA-1, SSEA-4 and Tra-1-60. To confirm that hESCs are not altered by their culture on Diff ${ }^{\text {MizhES6 }}$ cells, we subjected them to immunofluorescence microscopy to detect SSEA1, -4 and Tra-1-60 and AP expression as well as to RT-PCR to detect Oct-4, Nanog, Rex-1, Sox-2 and TERT expression. Of the surface markers, while SSEA-1 was not expressed, SSEA-4 and Tra-1-60 were strongly expressed (Figure 3D-U). The cells were also strongly positive for AP (Figure 3A, 3B and $3 C$ ). The RT-PCR data also showed normal expression of Oct-4, Nanog, Rex-1, Sox-2 and TERT (Figure 3V). These data strongly suggest that Diff ${ }^{\mathrm{N} Z \mathrm{HE} \text { ES6 }}$ cells successfully support the maintenance of all three hESC lines in an undifferentiated state.

\section{Analysis of the pluripotency of hESCs cultured on Diff ${ }^{\text {MzhES6 }}$ cells}

The pluripotency of the three hESC lines cultured on Diff ${ }^{\text {MizhES6 }}$ cells was analyzed by inducing them to differentiate in vitro into EBs and then analyzing the EBs by RT-PCR with primers specific for three different germ layers (ectoderm, mesoderm and endoderm). EBs were formed by culturing dissociated hESC clumps under suspension in EB media (Figure 4A). RT-PCR was performed on cells harvested before and 7 and 14 days after differentiation. The expression of the hESC-specific transcription factors Oct-4 and Nanog was dramatically downregulated as the days after EB formation increased. Concomitantly, the expression of embryonic germ layerspecific genes (NF-68 and keratin for ectoderm), (enolase and kallikrein for mesoderm) and ( $\alpha-\mathrm{FP}$ and $\alpha 1$-AT for endoderm) increased (Figure 4B). Thus, hESCs cultured on Diff ${ }^{\text {Mz-hes6 }}$ feeder cells maintained their pluripotency.

\section{Karyotypes of Diff ${ }^{\text {Mtz-hES6 }}$ feeder cells and hESCs cultured on Diff ${ }^{\text {mizhes6 }}$ cells}

Karyotype analysis of the Diff(izhES6 feeders and two

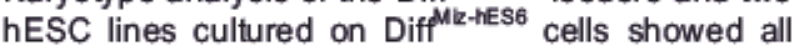
have normal karyotypes (HSF-6: 44+ XX, Miz-hES4: $44+\mathrm{XY}$, Diff ${ }^{\mathrm{Niz}-\mathrm{h} E s 6}$ feeder cells: $44+\mathrm{XX}$ ) (Figure 5A, 


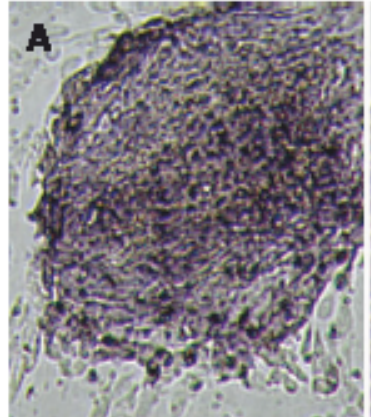

Mlz-hES1

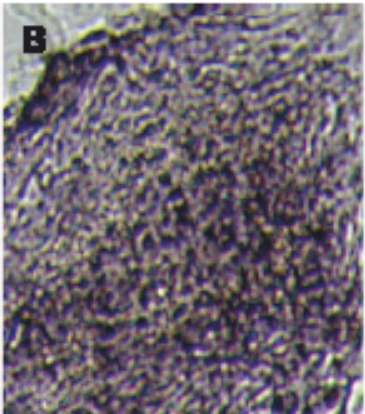

Mlz-hES4

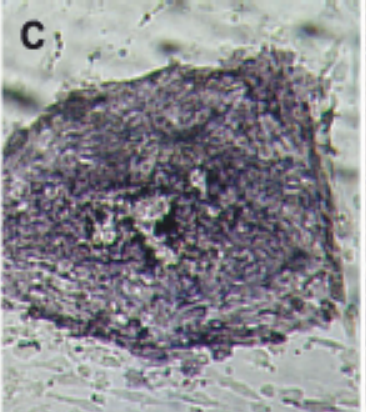

HSF-6

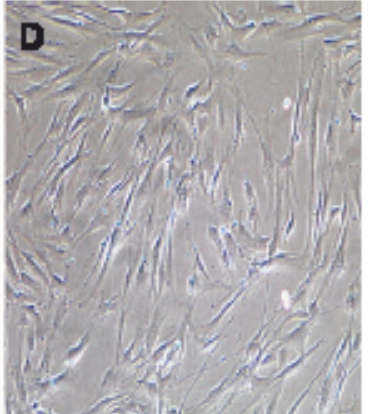

DIfI $^{\text {Miz-hESA }}$
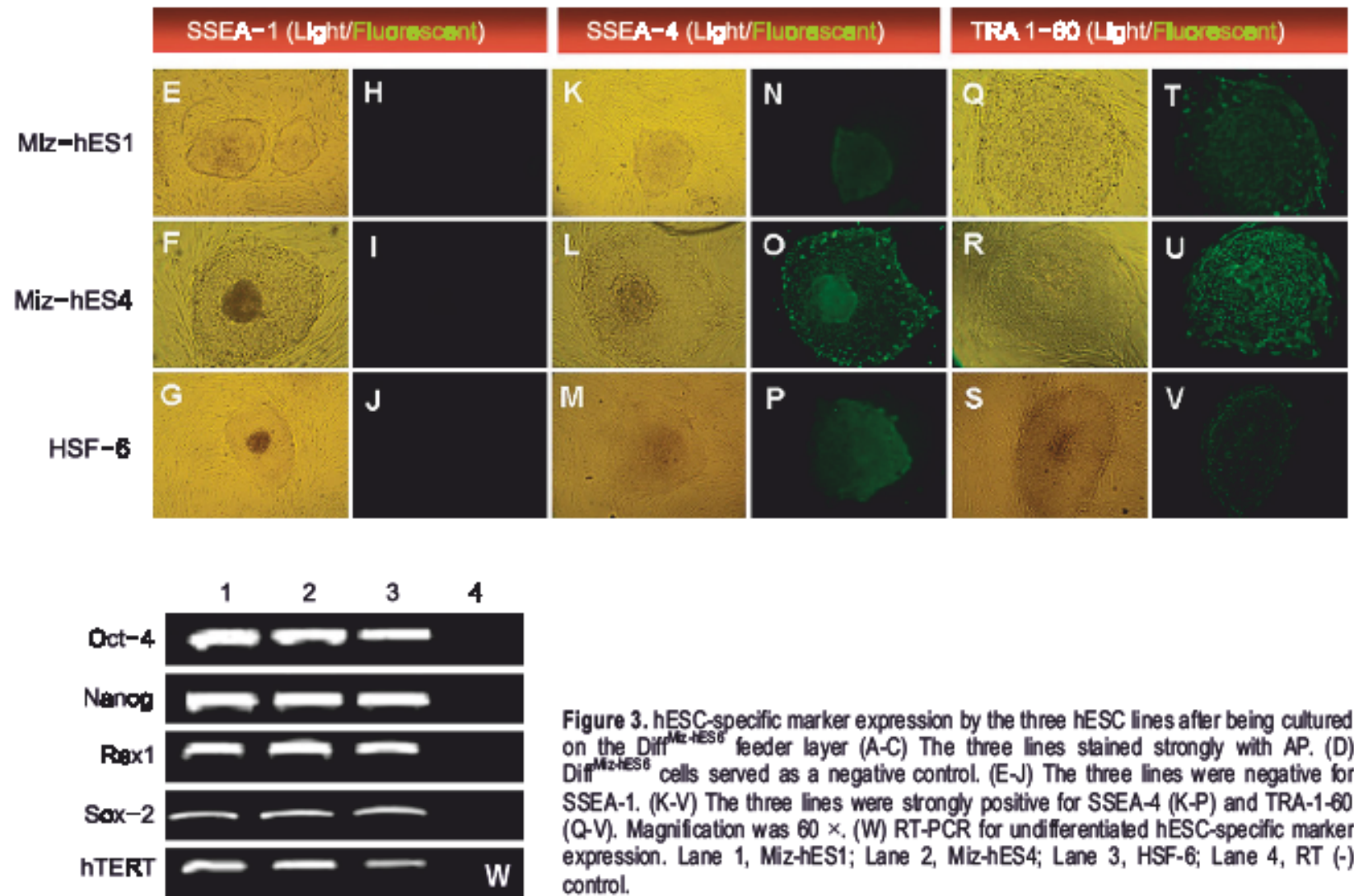

Figure 3. hESC-specific marker expression by the three hESC lines after being cultured on the Diff ${ }^{\text {tet }}$ (Es leeder layer (A-C) The three lines stained strongly with AP. (D) Diffiztess cells served as a negative control. (EV) The three lines were negative for SSEA-1. (K-V) The three lines were strongly positive for SSEA-4 (K-P) and TRA-1-60 (Q-V). Magnification was $60 \times$. (W) RT-PCR for undifferentialed hESC-specific marker expression. Lane 1, Miz-hES1; Lane 2, Miz-hES4; Lane 3, HSF-6; Lane 4, RT (-) control.

$5 B$ and $5 \mathrm{C}$ ). These results suggest that Diff ${ }^{\text {Miz-hES6 }}$ feeder cells successfully maintain hESCs without introducing any genefic abnormalities.

\section{Discussion}

hESCs require a feeder layer for their maintenance in an undifferentiated state. In conventional culture protocols for prolonged undifferentiated growth, the feeder layers are comprised of MEF cells. However, the routine propagation of hESCs on MEFs introduces the possibility of the transmission of mouse viruses, which is an impediment for the clincial application of these cells. To address this issue, previous studies have sought to develop a xeno-free support system for hESC culture by using donated human tissues (Richards et al., 2002; 2003). However, the use of human biopsies from fetal tissues raises ethical issues. The use of donated adult and neonatal tissues would be less ethically problematic but still would not be feasible for the mass production of hESCs; moreover, the use of different donors introduces an unwelcome variability into the culture system (Amit et al., 2003a; Hovatta et al., 2003; Lee et al., 2005). Furthermore, the risk of contamination 
A

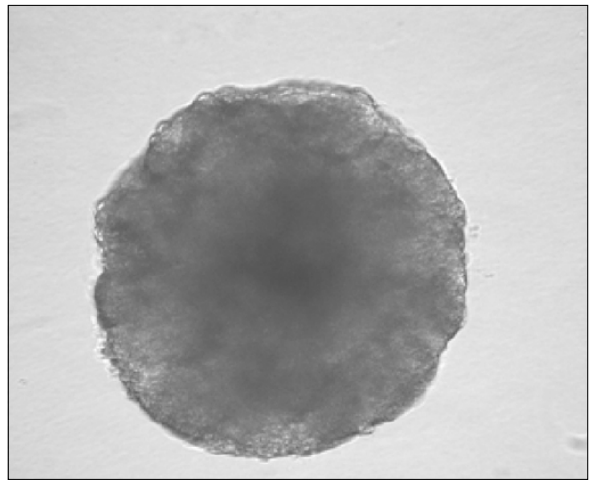

Miz-hES4

B

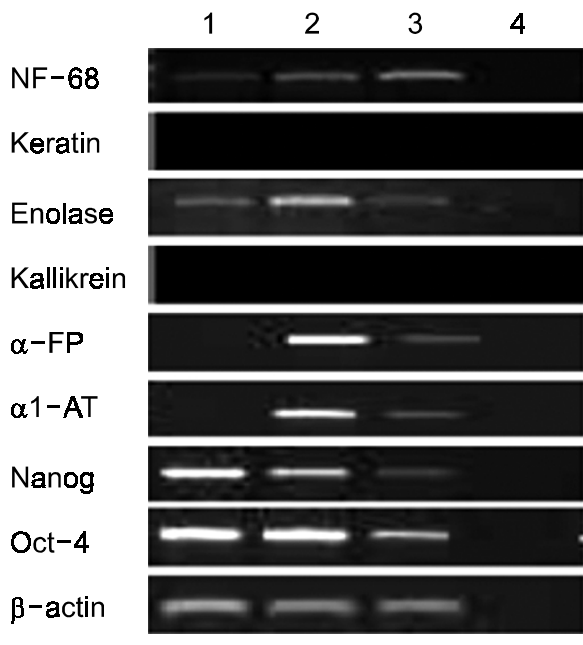

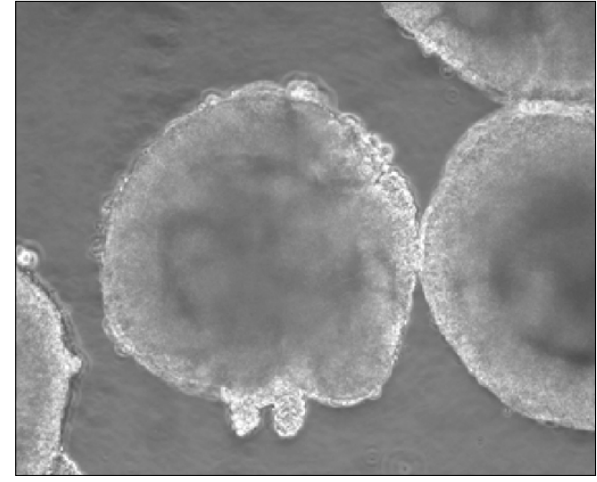

$\mathrm{HSF}-6$

C
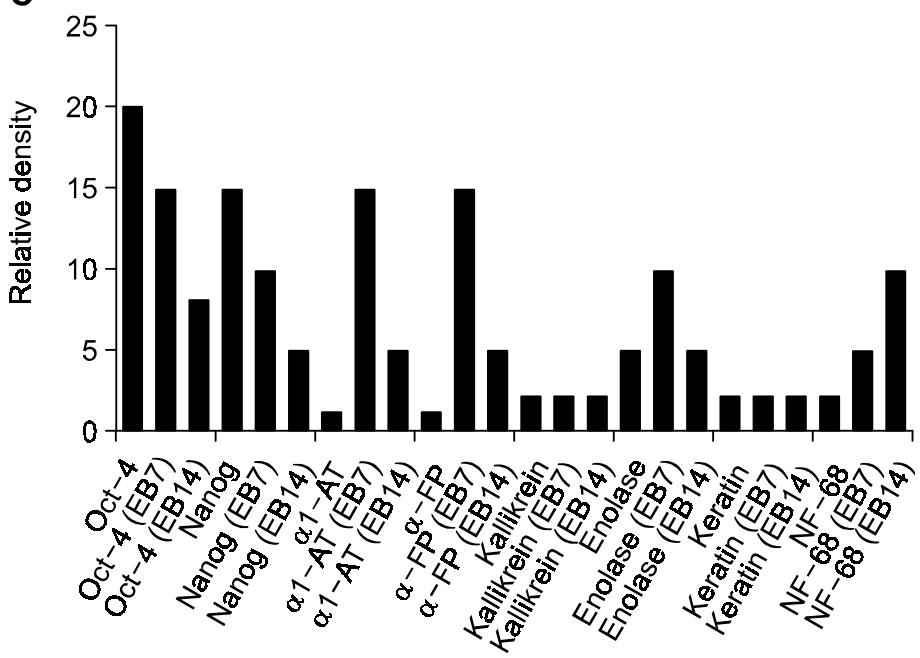

Marker gene (days after differentiation)

Figure 4. Ability of hESC lines grown on Diff $\quad{ }^{M i z-h E S 6}$ cells to differentiate into EBs. (A) Representative images of EBs formed from the Miz-hES4 (14-day-oldEB)andHSF-6(7-day-oldEB)hESClines.(B)AnalysisoftheundifferentiatedhESCsandtheEBs7and14daysafter entiation by RT-PCR using primers specific for three germlayers, namely, ectoderm(NF-68, Keratin), mesoderm (Enolase, Kallikr
$(\alpha-\mathrm{FP}, \alpha 1-\mathrm{AT})$. Oct-4 and Nanog served as undifferentiated hESC-specificmarkers. $\quad \beta$-actin served as a normalization control. The gel shows repretheir invitro differsentative results from HSF-6 cells. Lane 1, undifferentiated hESCs(HSF-6); Lane2, EB day 7 (HSF-6); Lane 3, EB day 14(HSF-6) ;Lane4, RT (-) control.Thegraphdepictsthesedataafterbandquantification.

with pathogens responsible for newly emerging human diseases, which cannot be screened for yet, remains. All of these concerns constitute serious challengesfortheclinicalapplicationofhESCs.

In the presentstudy, we developed a simple methodbywhich humanfeedercellscanbederived from hESCs. In this method, hESCs were continuously subcultured with DMEM/10\% FSC until they had a fibroblast-like appearance (about 3-5 passages), which came to be predominant under this culture condition.Duringtheirsubculture, theDiff ${ }^{\text {Miz-hES6 }}$ cells were cryopreserved. This led to sufficient Diff Miz-hES6 cellnumberstomeetthedemandoflong-termhESC culture. Moreover, the quality of the cells was relatively consistent, unlike feeders prepared from primary cultures orbiopsies (data notshown). Since the use of hESC-derived feeder cells obviates the need tosacrifice othertissuestosupplyfeedercells, this method eliminates many of the potential problems associated with other feeder cells, including the ethical issues, the possible transmission of mouse pathogens, and variabilty of the culture system that hampers comparisons between results obtainedbyusingdifferentfeedercells.

$\mathrm{Xu}$ et al., have recently reported that hTERT-immortalized fibroblast-like cells derived from hESCs (HEF1-hTERT) can support undifferentiated cell growth, while medium conditioned by HEF 1-hTERT cells permit the feeder-free culture ofhESCs (Xu al., 2004). However, hESCs cultured with HEF1- 

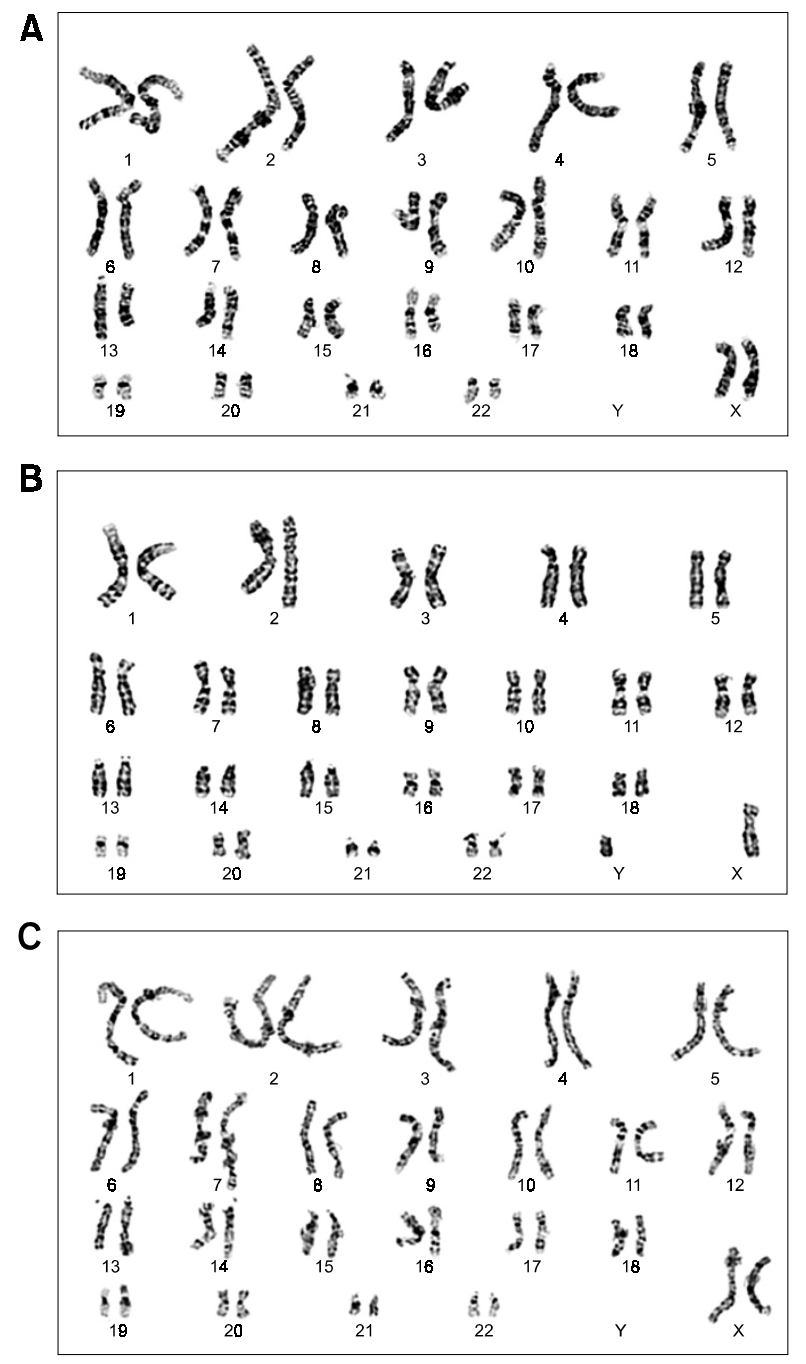

Figure 5. Karyotype analysis of the Diff ${ }^{\text {Miz-hES6 }}$ feeder cells and two hESClinesgrownonDiff Miz-hES6 feeders.(A)Diff Miz-hES6 feedercells(44 + XX).(B)HSF-6(44 + XX).(C)Miz-hES4(44 + XY).

hTERT feeder cells may have a higher likelihood of carcinogenesis due to the use of hTERT to immortalize the feeders. Consequently, Diff ${ }^{\text {Miz-hES6 }}$ feeder cells are safer for use in future cell replacement therapies.

WefoundthatexistinghESCsoriginallyestablished onMEFswereeasilyadapted to culture onDiff Miz-hES6 feeder cells. We also showed that these hESCderived fibroblast-like Diff ${ }^{\text {Miz-hES6 }}$ feeder cells support theprolonged, undifferentiatedmaintenanceofhESCs as efficientlyasMEFs.SupportofhESC growthwas demonstrated by assessing the morphology of the cells and by comprehensive analyses of hESC marker expression. We found that all three hESC lines we tested could be cultured on Diff Miz-hES6 feedercellsforatleast50passageswithoutanyloss of hESC-specific marker expression (Oct-4, Nanog, Rex-1, Sox-2, TERT, SSEA-1, SSEA-4 and Tra-1$60)$. In addition, the three hESC lines differentiated successfully into EBs thathad all three germ layers. Furthermore, the karyotypes of the Diff Miz-hES6 feeder cells and the hESCs cultured on Diff ${ }^{\text {Miz-hES6 }}$ feeder cells remained normal after long-term culture (over 50 passages). To avoid the possib ility off eedercell contamination during the preparation of the undifferentiated $h E S C$ s and EBs for the RT-PCR analyses described above, we performed RT-PCR using primers specific for a fibroblastmarker (prolyl4-hydroxylase $\beta$ ); fibroblast marker expression was never detected (data not shown). We have found previouslythathESCsculturedonMEFshaveacircular shape, whereas hESCs cultured on human feeder cellsarerelativelyirregularinshape(Richards etal., 2002; 2003; Amit etal., 2003a; Cheng etal., 2003; Hovatta etal., 2003; Lee etal., 2005). The reason for this difference is unclear. In this study, however, wefound that, likehESCsculturedonMEFs, hESCs cultured on Diff ${ }^{\mathrm{Miz}-\mathrm{hES}}{ }$ feeder cells were circular in shape and showed a prominent nucleus and nucleoli. The circular shape of hESCs cultured on Diff $^{\text {Miz-hES6 }}$ feeder cells, along with their equivalent passaging interval relative to hESCs cultured on MEFs (about 5 days), implies that the interaction between hESCs and the Diff Miz-hES6 feeder cells is similarandasefficientasitiswithMEFfeedercells. Ourobservationsshow the feasibility ofdeveloping a hESC culture system using autologous human feeder cells with minimal exposure to animal materials, which is a highly desirable system with regard totheapplication ofcellreplacementtherapy. Our system certainly eliminates the risk of contamination with mouse pathogens and unscreened pathogens responsible for newly emerging human diseases. However, our system did use FBS to culture the Diff ${ }^{\text {Miz-hES6 }}$ feeder cells. For complete xenofree culture ofhESCs, hESCs should be cultured at all times without any animal materials at all, including animal sera (FBS) and animal feeder cells. To date, while several other hESC culture systems using human feeder cells or conditioned medium with animal serum have been reported, animal serum (FBS)-free culture systems have not been reported. Therefore, webelievethatourpresenthESC culture system employing hESC-derived fibroblastlikefeedercellsrepresentssubstantialprogress with regard to developing the complete xeno-free culture system thatwould greatlyenhance the safety ofcell replacement therapy. Further investigations to develop this complete xeno-free hESC culture system arewarranted.

In conclusion, we developed a method by which autologoushESC-derivedDiff ${ }^{\text {Miz-hES6 }}$ feedercells can 
be obtained and used to successfully maintain hESC lines in an undifferentiated state. All three of the hESC lines we cultured on Diff ${ }^{\text {Miz-hES6 }}$ feeder cells proliferated efficiently, maintained their undifferentiated state, and retained their pluripotency. Even after long-term culture on Diff ${ }^{\mathrm{Miz}-\mathrm{hES} 6}$ feeder cells, the feeder cells and the hESCs cultured on these feeders had normal karyotypes. Therefore, we suggest that hESC-derived fibroblast-like Diff ${ }^{\text {Miz-hES6 }}$ feeder cells could be an efficient alternative for previously reported human feeder cells and could be useful as autologous feeders to produce stem cells for clinical applications (Heng et al., 2004). However, further investigation is needed to assess whether the hESCs cultured on Diff ${ }^{\text {Miz-hES6 }}$ feeder cells maintain their pluripotency in vivo with regard to teratoma formation. In addition, further development of this autologous culture system for hESC expansion such that it proceeds without the use of animal serum at any stage is highly desirable, as this complete xenofree system would promote the clinical applications of cell replacement therapy.

\section{Acknowledgment}

This research was supported by grants from the Stem Cell Research Center of the $21^{\text {st }}$ Century Frontier Research Program of the Korean Ministry of Science and Technology (SC2200). This project was supported by Korean Ministry of Education and Human Resources (2005).

\section{References}

Amit M, Margulets V, Segev H, Shariki K, Laevsky I, Coleman R, Itskovitz-Eldor J. Human feeder layers for human embryonic stem cells. Biol Reprod 2003a;68:2150-6

Amit M, Shariki C, Margulets V, Itskovitz-Eldor J. Feeder layer- and serum-free culture of human embryonic stem cells. Biol Reprod 2003b;70:837-45

Cheng L, Hammond H, Ye Z, Zhan X, Dravid G. Human adult marrow cells support prolonged expansion of human embryonic stem cells in culture. Stem Cells 2003;21:131-42

Choi SC, Yoon J, Shim WJ, Ro YM, Lim DS. 5-azacytidine induces cardiac differentiation of P19 embryonic stem cells. Exp Mol Med 2004;36:515- 23

Heng BC, Ng SC, Tong GQ. Human embryonic stem cellderived fibroblastic and epitheloid lineages as xeno-free support? In Vitro Cell Dev Biol - Animal 2004;40:129-30
Hovatta O, Mikkola M, Gertow K, Stromberg AM, Inzunza J, Hreinsson J, Rozell B, Blennow E, Andang M, AhrlundRichter L. A culture system using human foreskin fibroblasts as feeder cells allows production of human embryonic stem cells. Hum Reprod 2003;18:1404-9

Kim JH, Do HJ, Choi SJ, Cho HJ, Park KH, Yang HM, Lee SH, Kim DK, Kwak KB, Oh SK, Moon SY, Cha KY, Chung HM. Efficient gene delivery in diffeerentiated human embryonic stem cells. Exp Mol Med 2005a;37:36-44

Kim JH, Do HJ, Yang HM, Oh JH, Choi SJ, Kim DK, Cha KY, Chung HM, Overexpression of SOX9 in mouse embryonic stem cells directs the immediate chondrogenic commitment. Exp Mol Med 2005b;37:216-8

Kim SJ, Cheon SH, Yoo SJ, Kwon J, Park JH, Kim CG, Rhee KS, You S, Lee JY, Roh SI, Yoon HS. Contribution of the PI3K/Akt/PKB signal pathway to maintenance of selfrenewal in human embryonic stem cells. FEBS Lett 2005c; 579:534-40

Kim SJ, Lee JE, Park JH, Lee JB, Kim JM, Yoon BS, Song JM, Roh SI, Kim CG, Yoon HS. Efficient derivation of new human embryonic stem cell lines. Mol Cells 2005d;19:46-53

Lee JB, Lee JE, Park JH, Kim SJ, Kim MK, Roh SI, Yoon HS. Establishment and maintenance of human embryonic stem cell lines on human feeder cells derived from uterine endometrium under serum-free condition. Biol Reprod 2005; 72:42-9

Richards M, Fong CY, Chan WK, Wong PC, Bongso A. Human feeders support prolonged undifferentiated growth of human inner cell masses and embryonic stem cells. Nat Biotechnol 2002;20:933-6

Richards M, Tan S, Fong CY, Biswas A, Chan WK, Bongso A. Comparative evaluation of various human feeders for prolonged undifferentiated growth of human embryonic stem cells. Stem Cells 2003;21:546-56

Rosler ES, Fisk GJ, Ares X, Irving J, Miura T, Rao MS, Carpenter MK. Long-term culture of human embryonic stem cells in feeder-free conditions. Dev Dyn 2004;229:259-74

Thomson JA, Itskovitz-Eldor J, Shapiro SS, Waknitz MA, Swiergiel JJ, Marshall VS, Jones JM. Embryonic stem cell lines derived from human blastocysts. Science 1998;282: 1145-7

Xu C, Inokuma MS, Denham J, Golds K, Kundu P, Gold JD, Carpenter MK. Feeder-free growth of undifferentiated human embryonic stem cells. Nat Biotechnol 2001;19:971-4

Xu C, Jiang J, Sottile V, McWhir J, Lebkowski J, Carpenter MK. Immortalized fibroblast like cells derived from human embryonic stem cells support undifferentiated cell growth. Stem Cells 2004;22:972-80 